\title{
Liver metastasis in gastric cancer with particular reference to lymphatic advancement
}

\author{
Kazuhide Kumagai, Takayuki Tanaka, Kenichi Yamagata, Noboru Yokoyama, and Kouji Shimizu \\ Department of Surgery, Toyosu Hospital, Showa University, 4-1-18 Toyosu, Koto-ku, Tokyo 135-8577, Japan
}

\begin{abstract}
Background. We have previously reported that, in models of mesenteric lymph vessel obstruction in rats, we observed lymphaticovenous communication. This suggested that cancer cells metastasized to the liver by a lymphatic route. In the present study, we investigated the relationship between liver metastasis and lymphatic involvement in gastric carcinoma by examining resected specimens.

Methods. Twenty gastric cancer patients who had synchronous liver metastasis and 17 who developed metachronous liver metastasis after gastrectomy, performed between 1985 and 1997, were included in this study. They were compared with 44 advanced gastric cancer patients who had neither synchronous nor subsequent liver metastasis, and who survived with a disease-free course for more than 5 years. We compared the patients' clinicopathological features; in particular, we investigated extranodal invasion in the resected lymph nodes. This invasion was classified according to the pattern of extranodal cancer invasion, with or without rupture of the lymph node capsule.

Results. Liver metastasis was more frequent in patients with extranodal invasion than in those without extranodal invasion $(P<0.002)$. Multivariate analysis revealed that the correlation between extranodal invasion and liver metastasis was significant $(P<0.024)$; the odds ratio was 4.412 . Metastasis to the lymph nodes was the next most significant risk for liver metastasis.

Conclusion. We consider that the lymphatic system is closely related to the establishment of liver metastasis; in particular, extranodal invasion is a significant risk factor for liver metastasis in patients with gastric cancer.
\end{abstract}

Key words Gastric cancer · Liver metastasis · Lymphatic advancement $\cdot$ Extranodal invasion

Offprint requests to: K. Kumagai

Received: May 10, 2001 / Accepted: August 28, 2001

\section{Introduction}

Liver metastasis of gastric cancer significantly worsens the prognosis. Many studies have attempted to determine the mechanism by which such metastasis develops [1-4]. The most widely accepted theory is that the first step is the invasion and isolation of cancer cells from the primary tumor; the second step is intravasation; the third step is intravascular migration to the metastatic site; the fourth step is colonization in the blood vessel at the metastatic site; the fifth step is extravasation; and the sixth step is proliferation at the metastatic site. Recent technological advances in molecular biology seem to support this theory of the pathogenesis of liver metastasis [1-4]. However, liver metastasis of gastric cancer without venous invasion has been recognized. Some investigators have reported no relationship between liver metastasis and venous invasion [5,6]. It has been reported that lymphatic involvement is closely linked with liver metastasis $[7,8]$. We have previously reported that, in models of mesenteric lymph vessel obstruction in rats, we observed lymphaticovenous communication [9]. This suggested that cancer cells metastasized to the liver by a lymphatic route. In the present study, we investigated the relationship between lymphatic involvement and liver metastasis in patients with gastric cancer by examining resected specimens. In particular, extranodal invasion was examined in terms of retention of lymph flow caused by lymphatic obstruction.

\section{Patients and methods}

From 1985 to 1997, 380 consecutive patients with gastric cancer underwent gastric resection with lymph node dissection at the Department of Surgery, Toyosu Hospital, Showa University. There were 178 patients with early carcinoma (T1) and 202 with advanced carcinoma ( $\mathrm{T} 2$ or deeper invasion into the gastric wall). One hun- 
Table 1. Clinicopathological features of patients with liver metastasis

\begin{tabular}{|c|c|c|c|}
\hline Factors & $\begin{array}{c}\text { Synchronous } \\
\text { liver } \\
\text { metastasis }\end{array}$ & $\begin{array}{c}\text { Metachronous } \\
\text { liver } \\
\text { metastasis }\end{array}$ & $P$ value \\
\hline \multicolumn{4}{|l|}{ Sex } \\
\hline Male & 15 & 12 & \multirow[t]{2}{*}{0.7633} \\
\hline Female & 5 & 5 & \\
\hline \multicolumn{4}{|l|}{ Age (years) } \\
\hline Average & $65.0 \pm 10.7$ & $65.7 \pm 10.4$ & 0.8560 \\
\hline \multicolumn{4}{|l|}{ Tumor location } \\
\hline Upper & 7 & 6 & \multirow[t]{3}{*}{0.9992} \\
\hline Middle & 6 & 5 & \\
\hline Lower & 7 & 6 & \\
\hline \multicolumn{4}{|l|}{ Tumor size (mm) } \\
\hline$<50 \mathrm{~mm}$ & 5 & 7 & \multirow[t]{2}{*}{0.2949} \\
\hline$\geqq 50 \mathrm{~m}$ & 15 & 10 & \\
\hline \multicolumn{4}{|l|}{ Tumor type } \\
\hline Circumscribed & 5 & 10 & \multirow[t]{2}{*}{0.0368} \\
\hline Infiltrative & 15 & 7 & \\
\hline \multicolumn{4}{|l|}{ Histology } \\
\hline Differentiated & 8 & 9 & \multirow[t]{2}{*}{0.4312} \\
\hline Undifferentiated & 12 & 8 & \\
\hline \multicolumn{4}{|l|}{ Tumor depth } \\
\hline $\mathrm{sm}, \mathrm{mp}$ & 0 & 3 & \multirow[t]{3}{*}{0.1307} \\
\hline ss & 3 & 3 & \\
\hline $\mathrm{se}^{\sim}$ & 17 & 11 & \\
\hline \multicolumn{4}{|c|}{ Lymph node metastasis } \\
\hline Positive & 19 & 14 & \multirow[t]{2}{*}{0.4818} \\
\hline Negative & 1 & 3 & \\
\hline \multicolumn{4}{|c|}{ Lymphatic involvement } \\
\hline Positive & 16 & 14 & \multirow[t]{2}{*}{0.8111} \\
\hline Negative & 4 & 3 & \\
\hline \multicolumn{4}{|l|}{ Vascular involvement } \\
\hline Positive & 6 & 4 & \multirow[t]{2}{*}{0.9440} \\
\hline Negative & 14 & 13 & \\
\hline \multicolumn{4}{|l|}{ Extranodal invasion } \\
\hline Positive & 9 & 6 & \multirow[t]{2}{*}{0.5490} \\
\hline Negative & 11 & 11 & \\
\hline
\end{tabular}

sm, Invasion to submucosa; $\mathrm{mp}$, invasion to muscularis propria; ss, invasion to subserosa; $\mathrm{se}^{\sim}$, invasion to serosa, or exposed and adjacent

dred and five patients underwent total gastrectomy, 263 had subtotal distal gastrectomy, and 12 had various other operations, including proximal gastrectomy. The extent of lymph node dissection was: grade D3 (extended lymph node dissection) in 45; grade D2 (standard lymph node dissection) in 219; and grade D1 (perigastric lymph node dissection) in 116. Of these 380 patients, 20 patients who had synchronous liver metastasis and 17 patients who developed metachronous liver metastasis after surgery with gastric resection were included in this study (Table 1). We compared the clinicopathological features and behavior of lymph node metastasis (in particular, extranodal invasion) in these 37 patients with the findings in 44 patients who underwent resection for advanced gastric carcinoma during the same period and who survived with a disease-free course for more than 5 years. These 44 patients had no synchronous metastasis, nor did they develop metachronous metastasis. Extranodal invasion was classified according to patterns of lymph node capsule rupture. We classified extranodal invasion into three types, as follows: in type 1 there is rupture of the capsule of the metastatic lymph node, followed by infiltration around the lymph node; in type 2 there is infiltration around the metastatic lymph node and associated lymph vessels without rupture of the capsule; and in type 3 there is infiltration around a non-metastatic lymph node (Fig. 1). For histopathologic staining, we used hematoxylin-eosin (H\&E), and on some samples, Victoria blue plus H\&E double-staining.

In our statistical analysis we used the coded $\chi^{2}$ test to compare categorical variables, Student's $t$-test for univariate analysis, and the logistic regression model for multivariate analysis. Differences at $P<0.05$ were con- 
Type 1

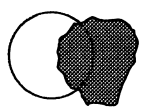

Type 2

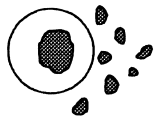

Type 3

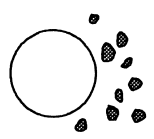

Breakage of the capsule of lymph node metastasis

and infiltration around the lymph node

Infiltration around the metastatic lymph node and

associated lymph vessels without rupture of the capsule sidered significant. The description of gastric cancer was in accordance with the Japanese classification of gastric carcinoma [10].

\section{Results}

\section{Comparison of synchronous and metachronous groups}

We compared the clinicopathological features of the synchronous group, who had liver metastasis at the time of surgery, with those of the metachronous group, in whom liver metastasis, detected by relaparotomy, computed tomography (CT), and/or magnetic resonance imaging (MRI) occurred postoperatively. There were no significant differences between these two groups with respect to sex, age, tumor location, tumor size, histopathologic type, tumor depth, lymph node metastasis, lymphatic involvement, venous involvement, or extranodal invasion; tumor type based on gross morphology was significantly different between the groups (Table 1).

\section{Comparison of liver metastasis and control groups}

We compared the clinicopathological features of the liver metastasis group (patients with liver metastasis) with those of the control group (patients without liver metastasis). We found no significant differences in sex, age, tumor location, tumor type, histopathologic type (differentiated or undifferentiated), lymphatic involvement, or venous involvement between the two groups. However, univariate analysis of the clinicopathological features showed that liver metastasis occurred significantly more frequently in the following patients: those with lesions more than $50 \mathrm{~mm}$ in diameter $(P<0.028)$, those with lymph node metastasis $(P<0.009)$, and those with lesions that had extranodal invasion $(P<$ 0.002) (Table 2).

These significant factors were subjected to multivariate analysis. The results revealed that extranodal invasion was a significant factor in liver metastasis $(P<$
0.024); the odds ratio was 4.412 (Table 3 ). We then excluded extranodal invasion and analyzed the other factors. We found that metastasis to the lymph nodes was the next most significant risk for the development of liver metastasis $(P<0.047)$; the odds ratio was 3.712 (Table 4).

\section{Extranodal invasion}

We defined the patterns of extension of cancer cells around the lymph node. The situation in which cancer cells do not invade around the lymph nodes was termed "extranodal negative". Those lesions in which cancer cells had invaded around the lymph nodes were termed "extranodal positive". We classified the forms of extranodal positive lesions into the three types mentioned above. In our study group of 37 patients with liver metastasis and 44 patients without liver metastasis, we recognized extranodal growth in 19 patients. The incidence of extranodal invasion in patients with either synchronous or metachronous liver metastasis was higher than that in patients without liver metastasis $(45.0 \%, 35.3 \%$, and $9.1 \%$, respectively) (Tables 1,2$)$. In patients with liver metastasis, we recognized 4 with type 1 invasion, and 11 with type 2 (Table 5). Thus, type 2 invasion, i.e., infiltration around a metastatic lymph node and its associated lymph vessels, was found in the majority of cases.

\section{Discussion}

Although the prognosis for gastric carcinoma has improved with earlier diagnosis and radical regional lymphadenectomy, the prognosis for gastric cancer with liver metastasis remains poor. Concerning the mechanism by which liver metastasis develops, the most generally accepted theory is that this metastasis occurs by the hematogenous route. This mechanism of liver metastasis has been supported by both clinicopathological analyses of resected specimens, showing a relationship between venous invasion and liver metastasis [11], and 
Table 2. Comparison between liver metastasis group (patients with liver metastasis) and control group (patients without liver metastasis)

\begin{tabular}{|c|c|c|c|}
\hline Factors & $\begin{array}{l}\text { Liver metastasis- } \\
\text { positive }\end{array}$ & $\begin{array}{c}\text { Liver metastasis- } \\
\text { negative }\end{array}$ & $P$ value \\
\hline \multicolumn{4}{|l|}{ Sex } \\
\hline Male & 27 & 25 & \multirow[t]{2}{*}{0.1309} \\
\hline Female & 10 & 19 & \\
\hline \multicolumn{4}{|l|}{ Age (years) } \\
\hline Average & $65.3 \pm 10.3$ & $60.8 \pm 6.9$ & 0.561 \\
\hline \multicolumn{4}{|l|}{ Tumor location } \\
\hline Upper & 13 & 17 & \multirow[t]{3}{*}{0.1943} \\
\hline Middle & 11 & 19 & \\
\hline Lower & 13 & 8 & \\
\hline \multicolumn{4}{|l|}{ Tumor size (mm) } \\
\hline$<50 \mathrm{~mm}$ & 12 & 25 & \multirow[t]{2}{*}{0.0282} \\
\hline$\geqq 50 \mathrm{~m}$ & 25 & 19 & \\
\hline \multicolumn{4}{|l|}{ Tumor type } \\
\hline Circumscribed & 15 & 15 & \multirow[t]{2}{*}{0.5493} \\
\hline Infiltrative & 22 & 29 & \\
\hline \multicolumn{4}{|l|}{ Histology } \\
\hline Differentiated & 17 & 15 & \multirow[t]{2}{*}{0.2770} \\
\hline Undifferentiated & 20 & 29 & \\
\hline \multicolumn{4}{|l|}{ Tumor depth } \\
\hline $\mathrm{sm}, \mathrm{mp}$ & 3 & 10 & \multirow[t]{3}{*}{0.1051} \\
\hline ss & 6 & 10 & \\
\hline $\mathrm{se}^{\sim}$ & 28 & 24 & \\
\hline \multicolumn{4}{|c|}{ Lymph node metastasis } \\
\hline Positive & 33 & 27 & \multirow[t]{2}{*}{0.0095} \\
\hline Negative & 4 & 17 & \\
\hline \multicolumn{4}{|c|}{ Lymphatic involvement } \\
\hline Positive & 24 & 21 & \multirow[t]{2}{*}{0.1221} \\
\hline Negative & 13 & 23 & \\
\hline \multicolumn{4}{|c|}{ Vascular involvement } \\
\hline Positive & 10 & 6 & \multirow[t]{2}{*}{0.1316} \\
\hline Negative & 27 & 38 & \\
\hline \multicolumn{4}{|l|}{ Extranodal invasion } \\
\hline Positive & 15 & 4 & \multirow[t]{2}{*}{0.0022} \\
\hline Negative & 22 & 40 & \\
\hline
\end{tabular}

sm, Invasion to submucosa; mp, invasion to muscularis propria; ss, invasion to subserosa; $\mathrm{se}^{\sim}$, invasion to serosa or exposed and adjacent

Table 3. Multivariate analysis of clinicopathological factors

\begin{tabular}{lccc}
\hline Factors & $P$ value & Odds ratio & $\begin{array}{c}\text { Confidence } \\
\text { interval }\end{array}$ \\
\hline $\begin{array}{l}\text { Depth of invasion } \\
\text { Tumor size }\end{array}$ & 0.5857 & 1.332 & $0.475-3.738$ \\
$\begin{array}{l}\text { Lymph node } \\
\quad \text { metastasis }\end{array}$ & 0.5597 & 1.416 & $0.44-4.553$ \\
$\begin{array}{l}\text { Extranodal } \\
\quad \text { invasion }\end{array}$ & 0.1209 & 2.909 & $0.755-11.215$ \\
& & & \\
\hline
\end{tabular}

by recently developed techniques in molecular biology (elucidation of, for example, adhesion molecules and angiogenetic factors) [1-3]. Venous invasion is considered to be closely related to liver metastasis [11,12], although occasionally venous invasion cannot be identi-
Table 4. Multivariate analysis of clinicopathological factors except for extranodal invasion

\begin{tabular}{lccc}
\hline Factors & & & Confidence \\
& $P$ value & Odds ratio & interval \\
\hline $\begin{array}{l}\text { Depth of invasion } \\
\text { Tumor size }\end{array}$ & 0.498 & 1.332 & $0.52-3.844$ \\
$\begin{array}{l}\text { Lymph node } \\
\text { metastasis }\end{array}$ & 0.2554 & 1.901 & $0.628-5.755$ \\
\hline
\end{tabular}

fied in the surgical specimens of patients with liver metastasis. The significance of blood vessel invasion has been debated. Maehara et al. [7,8] reported that they had found the concomitant presence of lymph node metastasis with liver metastasis, and they suggested that 
Table 5. Frequency of the type of extranodal invasion

\begin{tabular}{lccc}
\hline $\begin{array}{l}\text { Type of } \\
\text { extranodal } \\
\text { invasion }\end{array}$ & $\begin{array}{c}\text { Synchronous } \\
\text { liver } \\
\text { metastasis }\end{array}$ & $\begin{array}{c}\text { Metachronous } \\
\text { liver } \\
\text { metastasis }\end{array}$ & Control \\
\hline Type 1 & 3 & 1 & 1 \\
Type 2 & 6 & 5 & 2 \\
Type 3 & 0 & 0 & 1 \\
\hline
\end{tabular}

Control, Patients without liver metastasis; type 1, rupture of the metastatic lymph node capsule followed by infiltration around the lymph node; type 2, infiltration around the metastatic lymph node and associated lymph vessels without rupture of the capsule; type 3, infiltration around a non-metastatic lymph node

lymphatic advancement was related to liver metastasis, and that vascular invasion was an independent risk factor for liver metastasis of gastric cancer. Other reported findings in regard to liver metastasis have shown that the risk factor with the greatest significance was lymph node metastasis $[5,6]$ and that the proportion of liver metastasis increased with an increased degree of lymph node metastasis. Also, liver metastasis accounted for $50 \%$ of the recurrences in early gastric carcinoma [13]. The majority of patients with early gastric cancer with recurrence and liver metastasis had lymph node involvement $[14,15]$.

Burn [16] reported the phenomenon of lymphaticovenous communication when a lymph vessel is obstructed. He hypothesized that lymphaticovenous communication occurs when cancer cells metastasize to a lymph node or lymph vessel and obstruct the flow of lymphatic fluid. He referred to the possibility of liver metastasis occurring by a lymphatic route. In our previous study, we confirmed the formation of lymphaticovenous communication, using mesenteric lymphatic obstruction in rats, and reported the possibility that liver metastasis occurred by a lymphatic route [9]. From these findings, we considered that tumor cell obstruction in lymph vessels led to the establishment of liver metastasis, and, therefore, we studied extranodal invasion in resected specimens. There have been many reports of extranodal invasion, but few related to gastric cancer. It is well known that extranodal invasion is an important indicator of poor prognosis in cancers of the pharynx, larynx, thyroid, lung, and breast [17-21].

It has been reported that extranodal invasion is an indicator of distant metastasis in patients with head, neck, or vaginal cancers [19,22]. Concerning gastrointestinal cancers, it has also been reported that extranodal invasion indicates a poor prognosis and a risk of local recurrence in patients with rectal cancer [23]. In our present study, 15 of 37 patients with liver metastasis $(41 \%)$ had extranodal invasion $(P<0.002)$. The odds ratio for extranodal invasion was 4.412. As stated above, we classified extranodal invasion into three types: type 1 , in which the capsule of the metastatic lymph node ruptured, leading to infiltration around the lymph node (this occurred in $26.7 \%$ ); type 2, in which there was infiltration around a metastatic lymph node and its lymph vessels (this occurred in $73.3 \%$ ). The extranodal invasion seen in type 2 seems to indicate the retention of lymph and the elevation of endolymphatic pressure behind the obstruction. In the rat model, it seemed likely to be a mechanism of lymphaticovenous communication. Smith and Basu [24] demonstrated that neovascularization of the rabbit cornea after the injection of India ink led to the appearance of ink particles in the ipsilateral lymph nodes. These findings indicate that lymph-capillary anastomoses are present, and/or that angiogenesis correlates with the formation of new lymphatic vessels. In the situation in which there is lymph vessel obstruction by lymph node, or lymph vessel cancer involvement, we presume that the lymphaticovenous communication from the periphery to the main lymph system was patent. Although the complicated mechanisms of liver metastasis cannot be completely explained only by extranodal invasion, we found that extranodal invasion was the most highly significant risk factor for the development of liver metastasis, and was an indicator of poor prognosis. Thus it would appear that decisions regarding postoperative therapy for patients with extranodal invasion are both important and problematic.

\section{Conclusion}

We investigated the relationship between liver metastasis and lymphatic involvement in gastric carcinoma. We found that the lymphatic system was closely related to the establishment of liver metastasis; in particular, we found that extranodal invasion was a significant risk factor for liver metastasis. We discussed the mechanism of liver metastasis in gastric cancer, in terms of its relationship to lymph vessel obstruction and lymphaticovenous communication.

\section{References}

1. Liotta LA, Rao CN, Wewer UM. Biochemical interactions of tumor cells with the basement membrane. Ann Rev Biochem 1986;55:1037-57.

2. Takahashi U, Kitadai Y, Bucana CD, Cleary KR, Ellis LM. Expression of vascular endothelial growth factor and its receptor, $\mathrm{KDR}$, correlates with vascularity, metastasis, proliferation of human colon cancer. Cancer Res 1995;55:3964-8.

3. Radinsky R, Ellis LM. Molecular determinations in the biology of liver metastasis. Surg Oncol Clin North Am 1996;5:215-29.

4. Sumiyoshi Y, Yamashita Y, Maekawa T, Sakai N, Shirakusa T, Kikuchi M. Expression of CD44 vascular endothelial growth factor, and proliferating cell nuclear antigen in severe venous 
invasional colorectal cancer and its relationship to liver metastasis. Surg Today 2000;30:323-7.

5. Yamamura T, Matsuzaki H, Matsuoka H, Tanaka K, Kikuchi K, Oikawa $\mathrm{H}$, et al. Multivariate analysis on prognostic factors for recurrence after resection of colorectal cancer. J Jpn Soc Coloproctol 1997;50:130-5.

6. Heys SD, Sherif A, Bagley JS, Brittenden J, Smart C, Eremin O. Prognostic factors and survival of patients aged less than 45 years with colorectal cancer. Br J Surg 1994;81:685-8.

7. Maehara Y, Tomisaki S, Oda S, Sakaguchi Y, Ichiyoshi Y, Sugimachi K. Lymphatic advancement to peritoneal dissemination and liver metastasis in gastric cancer patients. Anticancer Res 1994;14:2755-8.

8. Maehara Y, Oshiro T, Baba H, Ohno S, Kohnoe S, Sugimachi K. Lymphatic invasion and potential for tumor growth and metastasis in patients with gastric cancer. Surgery 1995;117:380-5.

9. Yamagata K, Kumagai K, Shimizu K, Masuo K, Nishida Y, Yasui A. Gastrointestinal cancer metastasis and lymphogenous spread; viewpoint of animal models of lymphatic obstruction. Jpn J Clin Oncol 1998;28:104-6.

10. Japanese Research Society for Gastric Cancer. Japanese classification of gastric carcinoma. 1st English ed. Tokyo: Kanehara; 1995.

11. Nagai E, Yao T, Sakamoto M, Akazawa K, Utsunomiya T, Tsuneyoshi M. Risk factors related to liver metastasis in colorectal carcinoma: a multivariate analysis of clinicopathologic and immunohistochemical variables. Jpn J Cancer Res 1994;8 5:1280-7.

12. Noguchi Y. Blood vessel invasion in gastric carcinoma. Surgery 1990;107:140-8.

13. Ohta H, Takagi K, Noguchi Y, Nishi M, Kajitani T, Kato Y. Early gastric carcinoma with special reference to macroscopic classification. Cancer 1987;60:1099-106.

14. Ohta J, Takeda J, Koufuji K, Kodama I, Tsuji Y, Maruiwa M, et al. Early gastric cancer associated with synchronous multiple liver metastasis - two rare cases. Kurume Med J 1993;40:414.

15. Nakata Y, Watanabe Y, Nakata T, Kimura K, Sato M, Kawachi I. Early gastric cancer associated with synchronous liver metastasis and portal tumorous embolism: report of a case. Surg Today 1998;28:753-7.

16. Burn JI. Obstructive lymphopathy. Ann R Coll Surg Engl 1968;42:93-113.

17. Aijaz A, Jonas TJ. Extracapsular spread in the clinically negative neck (N0): implications and outcome. Otolaryngol Head Neck Surg 1996;114:65-70.

18. Hirabayashi H, Koshii $\mathrm{K}$, Uno $\mathrm{K}$, Ohgaki H, Nakasone $\mathrm{Y}$, Fujisawa T. Extracapsular spread of squamous cell carcinoma in neck lymph nodes: prognostic factor of laryngeal cancer. Laryngoscope 1991;101:502-6.

19. Yamashita H, Noguchi S, Murakami N. Extracapsular invasion of lymph node metastasis is an indicator of distant metastasis and poor prognosis in patients with thyroid papillary carcinoma. Cancer 1997;80:2268-72.

20. Bollen EC, Theunissen PH, van Duin CJ, Drenth BM, van Noord JA, Blijham GH. Clinical significance of intranodal growth in lymph node metastases of non-small cell lung cancer. Scand J Thor Cardiovasc Surg 1994;28:97-102.

21. Mambo NC, Gallager HS. Carcinoma of the breast: the prognostic significance of extranodal extension of axillary disease. Cancer 1977;39:2280-5.

22. Van der Velden J, van Lindert CM, Lammes FB, ten Kate FJ, Sie-Go DM, Oosting H, et al. Extracapsular growth of lymph node metastases in squamous cell carcinoma of the vulva. Cancer 1995; 75:2885-90.

23. Ueno H, Mochizuki H, Takakuma S. Prognostic significance of extranodal microscopic foci discontinuous with primary lesion in rectal cancer. Dis Colon Rectum 1998;41:55-61.

24. Smith SS, Basu PK. Mast cells in corneal immune reaction. Can J Ophthalmol 1970;5:175-83. 